\title{
MANUALES DE LECTURA Y PACIFICACIÓN NACIONAL DURANTE EL ÚLTIMO POSTCONFLICTO EN COLOMBIA
}

\author{
Luis Rubén Pérez Pinzón
}




\section{READING MANUAL AND NATIONAL PACIFICATION DURING THE LAST POST-CONFLICT IN COLOMBIA}

\begin{abstract}
The teaching strategies used to consolidate the post-conflict and peace in the country after the last civil war in Colombia (1899-1902), from a descriptive perspective and contrast of resources allow to recognize the role played by each book, every heroic or moral reading divulged in the compulsory reading texts in the schools and colleges in Colombia, after 1902. To that purpose, the article showed the importance of public investment on the speech of the winners, the creation of religious editorials for unification of contents and promotion of new readings and patriotic histories about Colombia, and the editorial efforts of the vanquished after the Thousand Days' War. Specifically, the publications by veterans like Joaquin Quijano and Enrique Otero, who unveiled their version of the events and reaffirmed the importance of the peace process and national reconciliation from a perspective of patriotism.
\end{abstract}

Key words: Postconflict, public education, publishing technology, literary subjectivity

\section{AUTOR}

\section{Luis Rubén Pérez Pinzón}

Postdoctor en Historia Tecana American University.

Docente investigador y tutor del Semillero de Investigación en Literatura del Estado Nacional y el Conflicto Interno (Silencio) adscrito al Grupo TCP Universidad Autónoma de Bucaramanga

Correo electrónico: Iperez14@unab.edu.co

\section{RESUMEN}

Las estrategias didácticas empleadas para la consolidación del postconflicto y la pacificación del país después de la última guerra civil de Colombia (18991902), desde una perspectiva descriptiva y mediante un contraste de fuentes permiten reconocer el papel que cumplió cada libro, cada lectura heroica o moral divulgada en los textos de lectura de uso obligatorio en las escuelas y colegios de Colombia después de 1902. Para tal fin, se demuestra la importancia de las inversiones públicas sobre el discurso de los vencedores, el surgimiento de las editoriales religiosas de censura y unificación de contenidos que promovieron nuevas lecturas e historias patrias sobre Colombia, así como los esfuerzos editoriales de los vencidos después de la Guerra de los Mil Días. Específicamente las publicaciones de excombatientes como Joaquín Quijano y Enrique Otero, quienes dieron a conocer su versión sobre lo acontecido y reafirmaron la importancia de los procesos de paz y la pacificación nacional desde una perspectiva de amor a la patria.

Palabras clave: Postconflicto, educación pública, tecnología editorial, subjetividad literaria.
Recibido: 28/06/2016

Aprobado: $31 / 10 / 2016$ 


\section{INTRODUCCION ${ }^{1}$}

Uno de los combatientes más temidos y olvidados por las familias andinas que se enfrentaron durante la Guerra de los Mil Días, optó en sus memorias heroicas (escritas con un seudónimo literario) negar toda intención por recordar y evitar cualquier interés por sus acciones guerrilleras en la toma y control del corredor militar que iba desde Palonegro hasta el río Sogamoso.

Alcanzada la anhelada condición de empresario próspero de los valles del Magdalena, quien vivía el pleno disfrute de una vida incuestionable y moralmente respetada por su buen nombre y prestigio como industrial petrolero, al General liberal José Rosario Díaz no le interesaba que su apología a la innovación y el esfuerzo empresarial se viese manchada por sus delitos, crímenes y sevicia con la que enfrentó al enemigo godo desde los últimos meses de 1899.

De allí que en el texto autobiográfico que publicó de forma rústica y humilde advirtiese a sus hijos y conocidos su desinterés por evitar la deshonra a sus descendientes, se negaba a rememorar lo que había vívido, ordenado y actuado durante su más cruenta guerra civil. Con franqueza les expresaba: "Quisiera hacer relación de mis campañas pero son 5 y muy largas y contienen recuerdos tan amargos, que es mejor dejarlos para narrarlos separadamente en otra obra" (Anónimo, 1934, p. 41).

Sin embargo, esa actitud de rechazo y olvido a lo vivido y cometido no fue compartida por otros excombatientes, quienes desde su condición de hombres prósperos y letrados aprovecharon tanto la República Conservadora como a la República Liberal para recordar a sus camaradas, copartidarios y familiares las razones de sus creencias, acciones, luchas y renuncia a las armas durante el postconflicto iniciado después de 1902, para justificar las causas de las victorias del oficialismo como para cuestionar las decisiones de los jefes que llevaron a la derrota del "ejército revolucionario" (Pérez, 2015a).

Apelando a las licencias editoriales y a la aprobación de la censura religiosa, los literatos más comprometidos con el proceso de pacificación y reunificación de la Nación optaron por emplear sus vivencias, recuerdos y ficciones para cuestionar las razones y consecuencias de la guerra como camino para solucionar los conflictos y diferencias entre los colombianos, siendo algunas de esas reflexiones seleccionadas y compiladas en las antologías de lecturas que el Gobierno Nacional autorizó publicar, divulgar o emplear en las escuelas públicas como manuales de lectura para la educación elemental y superior (Pérez, 2015b).

Resultado de los proyectos La guerra civil de 1899 a través de la narrativa literaria de Santander (Unab 134056) y Empresarismo y prácticas ciudadanas de los inmigrantes europeos en Colombia (Unab 156018), financiados por la Universidad Autónoma de Bucaramanga como parte de sus convocatorias internas de investigación, en los siguientes apartados se da respuesta a preguntas - problemas como: ¿cuál fue el papel que cumplió cada libro, cada lectura heroica o moral divulgada en los textos de lectura de uso obligatorio en las escuelas y colegios de Colombia después de 1902?, ¿cómo se divulgaron los discursos de los vencedores, las editoriales religiosas de censura y los esfuerzos editoriales de los vencidos?

\footnotetext{
${ }^{1}$ Artículo resultado de los proyectos de investigación Unab I34056 e I56018, el cual fue presentado como ponencia en el I Congreso Internacional de Educación y IV Congreso Iberoamericano de Pedagogía y Educación Especial. Pamplona (Colombia), Universidad de Pamplona, junio 2 de 2016. [Eje temático: El papel de la educación en el postconflicto]
} 


\section{METODOLOGÍA}

La investigación que originó el nuevo producto de conocimiento corresponde a un estudio formal asociado con una investigación bibliográfica y documental, basada en el contraste y la crítica hermenéutica de fuentes, desde un enfoque cualitativo y una perspectiva descriptiva (o monovariable).

En la muestra de cincuenta textos literarios seleccionada para el estudio se identificó la tendencia de relatos que apelan a la vivencia personal como a la ficción literaria fundada en vivencias personales ocultas en las acciones de cada uno de los personajes creados. De allí que se optara por interpretar cada uno de los textos desde los principales constructos de la subjetividad literaria: la autofiguración y la autorepresentación.

Es decir, los escritores de la guerra y el postconflicto de 1902 lograron con sus testimonios, reconstrucciones y ficciones, la divulgación de "los secretos más íntimos - las vivencias más recónditas de quien nos hace partícipes de su propia vida" (Pérez, 1996). Para ello apelaron en su mayoría a la composición de novelas históricas matizadas por biografías en las cuales de forma directa (autofiguración) o indirecta (autorepresentación) lograron la exteriorización y contextualización de sí mismos como ciudadanos, empresarios, dirigentes o combatientes dando prevalencia a su visión personal sobre lo acontecido. Y con ello apelaron a la libertad de describir, interpretar y cuestionar lo ocurrido como partícipes de lo vivido sin estar condicionados al contraste de su relato con otras fuentes, testigos o publicaciones sobre los mismos hechos (Pérez, 2014).

Considerando la descendencia, parentesco o afinidad con los inmigrantes europeos de los autores a estudiar, al seguir los referentes teóricos de Georges May resulta necesario reafirmar que la autofiguración devela el relato íntimo y directo que un escritor hace en su día a día sobre todo aquello que le acontece, sucede o influencia recurriendo para ello a la escritura de crónicas, cartas, memorias o diarios (íntimos u oficiales). La autorepresentación, por el contrario, se caracteriza por ser el relato sobre lo vivido mediante el cual el autor resguarda u oculta parcial o plenamente su identidad y prestigio al recrear lo acontecido por medio de géneros como los cuentos, novelas y relatos en los cuales personajes opuestos a su personalidad o condición social, política o económica viven situaciones semejantes a las experimentadas por el narrador con el fin de propiciar reflexiones éticas o juicios críticos sobre su pasado (May, 1982).

Autofiguración y autorepresentación son en suma expresiones opuestas del mismo género acerca de un mismo acontecimiento, fenómeno o personaje recreado desde la perspectiva individual de un ser contemporáneo al mismo, razón por la cual, "la autobiografía real o fantástica, en prosa o en verso, constituye aquí y en cualquier parte, un valioso documento que contiene y transmite, con rasgos singulares e inconfundibles, el sentimiento de lo estrictamente individual" (Pérez, 1972).

Siguiendo a autores como Vicente Pérez, Georges May, Mario Jursich Durán, entre otros, las creaciones biográficas se caracterizan fundamentalmente por la escritura o narración en primera persona del singular. Los puntos de vista están fundados en la retrospectiva de lo vivido, resulta constante la intromisión o prevalencia de sus preocupaciones, obsesiones o posiciones ideológicas, así como la individualidad se antepone a las preocupaciones político-económicas o socio-culturales del contexto aunque los textos pueden 
develar el rol y status social alcanzado (memoria documentada). O por el contrario, el papel que tuvieron las vivencias narradas para alcanzar desde el anonimato, la identidad y madurez social a partir del recuerdo melancólico o la fantasía recreadora de lo acontecido en un contexto de común conocimiento (recuerdo distorsionado o relato manipulado) (Pérez, 2014).

Al escribir el biógrafo para satisfacer su necesidad de narrar lo acontecido al mismo tiempo se constituye en lector recurrente de su memoria para reafirmar sus convicciones al participar en las discusiones de los círculos literarios o las reuniones culturales partidistas, así como se promovió desde la lectura social de su perspectiva de pasado nuevas formas del imaginario y la memoria colectiva acorde al discurso del vencedor o el vencido, con lo cual, "inclinados sobre la espalda de Narciso vemos nuestro rostro, y no el suyo, reflejados en las aguas de la fuente" (May, 1972).

Vicente Pérez Silva al justificar la importancia de estudiar y compilar los textos biográficos que representaban a los personajes más reconocidos de las letras y las artes de Colombia, y con ello a las expresiones más directas del alma nacional, reconoció la función cultural de la autofiguración como de la autorepresentación de los autores a través de su vida personal-ejemplar o ejemplarizante- pues a través de los mismos se logra un acercamiento directo o indirecto a su "vida, ascendencia, nacimiento, crianza y aventuras" al constituirse en "manifestación creativa de quien la refiere, ya con carácter estrictamente histórico o bien con sabor estrictamente literario, y puede abarcar desde una obra de considerable extensión, hasta una simple crónica o apunte periodístico" (Pérez, 1996).

De allí que textos biográficos permitan validar su reflexión sobre el público para el cual se componían, divulgaban y publicaban durante el siglo XX al considerar que los mismos se escribían "con destino al público general o para un determinado núcleo de personas, en particular" (Pérez, 1996).

Siendo esas variaciones directamente relacionadas con la institución (o partido) que financiaba su publicación, el clima político que permitía o restringía la divulgación de las reflexiones personales sobre hechos colectivos acorde a las restricciones ideológicas y las censuras editoriales de los partidos y gobernantes en el poder, así como los canales comerciales o académicos de distribución, acceso, crítica y masificación. O por el contrario, de ocultamiento y limitación de su existencia y divulgación entre el público general (Pérez, 2014).

\section{RESULTADOS}

Después de la guerra civil entre criollos y chapetones (1810-1816), patriotas y realistas (1819-1824), Colombia no había podido vivir un ambiente de paz y tranquilidad consecuente a todo conflicto. Por el contrario, los odios, venganzas y deudas del último conflicto armado justificaban el inicio de nuevas afrentas y bandos armados aprovechando coyunturas económicas de crisis o circunstancias políticas excepcionales (Pérez, 2013).

Desde la Guerra de Independencia se habían reafirmado las prácticas coloniales de reclutamiento de varones aptos para servir como milicianos o soldados regulares. Al acostumbrado reclutamiento de uno o más miembros de cada familia, acorde con el padrón parroquial o municipal, se sumó el arresto y reclutamiento en los caminos públicos o sitio rural (leva). En las cabeceras urbanas, muchos hombres se enlistaron en los batallones o marcharon voluntariamente a los campos de batalla. Quienes se 
resistían o evadían su participación en cualquiera de los bandos eran cazados durante los días de mercado y misa al esperar los gobernantes o los comandantes rebeldes a que se introdujeran en la plaza principal para ser detenidos de forma selectiva, o en la mayoría de los casos, se cerraban las cuatro esquinas de salida para forzarlos uno a uno a firmar la lista de reclutamiento.

Una alternativa represiva para garantizar la libertad sin perder el orden constitucional impuesto por los regeneradores nacionalistas desde 1886 fue limitar la promoción y fomento de asociaciones políticas, conspiraciones, levantamientos y toda forma de alteración del orden público al adoptarse una Constitución Política que limitaba el uso de la prensa, establecía el uso de la censura previa, anteponía los valores morales y policivos a toda comunicación o expresión en cumplimiento del Concordato con la Santa Sede, tipificaba las formas de delito consecuentes al uso de la prensa, las imprentas y las comunicaciones escritas (1896), así como condicionaba al país regenerado a confiar solo en aquellos productos censurados por el clero y publicados en las imprentas de las comunidades religiosas con talleres tipográficos como eran los lasallistas, salesianos, jesuitas, entre otros (Pérez, 2012).

La constante condición de ser hombre, y por ende recluta, soldado o veterano de alguna de las guerras civiles, se constituyó en tema recurrente de los periodistas, publicistas y literatos que habiendo combatido en los campos de batalla regresaban a los campos de la política y la creación artística para cuestionar las prácticas belicistas con las que se presionaban cambios políticos, se imponían nuevos regímenes constitucionales y se propiciaban nuevos modelos económicos. Relatos compilados a mediados del siglo XX en manuales de lectura como la emblemática cartilla La Alegría de Leer publicada por la editorial religiosa Voluntad o el Curso Superior de Lectura de la editorial religiosa La Salle, siendo de destacar el poema Lágrima de soldado de Lorenzo María Lleras.

Abandonando su hogar, presto a sobrevivir a la guerra a la que se llamaba, Lleras rememora ese momento de tristeza y temor al expresar del típico soldado nacional:

\section{Desde el portal de la choza, de rodillas una hermosa \\ feliz viaje le desea, y su rubia trenza ondea de la brisa al soplo blando: e inmóvil queda mirando el soldado su dolor. última, tierna mirada, dulcemente acompañada} de una lágrima de amor, ique el pobre soldado limpió con rubor! (Pérez, 2014, p. 52).

Al editor como a la comunidad religiosa que gestionó la edición y popularización de esos textos les interesaba resaltar las historias personales, anónimas y desconocidas de los combatientes reales de cada guerra, cuyas acciones, temores y dolores eran irrelevantes ante el genio y figura que inspiraban los generales conservadores y los generalísimos liberales. Jefes de la vida y de la muerte quienes al concluir cada guerra, especialmente la que se extendió de 1899 a 1902, se dieron a la tarea de hacer sus propios recuentos, memorias e historias sobre lo que 
verdaderamente ocurrió, menospreciando así el número de soldados caídos, lisiados, extraviados o expulsados de sus lugares de origen como consecuencia de los odios mal firmados.

Las representaciones de la vida guerrera de los soldados de origen rural, reafirmada por los relatos literarios de intelectuales y combatientes activos a través de las auto representaciones cronísticas de Joaquín Quijano Mantilla o las auto figuraciones fantásticas de Enrique Otero D'Acosta (Pérez, 2016), recreaban el abandono que debían hacer los campesinos de sus parcelas, cultivos y familias para cumplir con las exigencias bélicas de los gobernantes, los hacendados en su condición de generales, así como los comandantes rebeldes que amenazaban acabar con sus bienes o sus seres queridos de no involucrarse en la defensa de la causa. De tal manera, las luchas partidistas por el poder monopólico del Estado por parte de las élites urbanas eran realmente asumidas con el sudor, hambre, sangre e incremento de la miseria entre las gentes comunes de las zonas rurales cercanas o de las provincias distantes (Pérez, 2014).

Las guerras civiles de finales del siglo XIX permitían recordar a los literatos como a los combatientes letrados e influyentes el origen, la formación y la consolidación de Colombia como una nación fruto del conflicto, la violencia y los enfrentamientos sangrientos entre conquistadores y conquistados, criollos y peninsulares, patriotas y realistas, reconquistadores y libertadores, monarquistas y republicanistas, liberales y conservadores, regeneradores y revolucionarios, republicanos y socialistas, etc. Destino manifiesto de una nación formada de la violencia conquistadora y conservada por medio de la violencia del orden estatal, respecto a la cual el laureado Aurelio Martínez Mutis en la compilación de F. Restrepo El castellano en los clásicos de la Editorial Librería Voluntad, expresaba:

Naciste, ioh patria! y desde entonces nada más que el dolor, la sangre y los vaivenes trágicos se divisa en tu jornada; grande es tu historia, y sin embargo vienes llorosa y triste, exangüe y enlutada; está en plena juventud, y tienes hilo de plata en las marchitas sienes y arrugas en la faz desencajada! (Pérez, 2014, p. 56).

A lo largo del siglo XIX, los colombianos resolvieron sus diferencias políticas e ideológicas a través de las guerras civiles, siendo la de los Mil Días la última expresión de esa práctica heredada de los Generales Supremos de mediados del siglo. Con cada guerra el Comandante General y su partido político vencedor impusieron una nueva constitución y un nuevo régimen político. Cada gran acción consecuente con los triunfos bélicos fue la reforma o sustitución de la constitución política del vencido. No obstante, las representaciones literarias compiladas o publicadas durante la primera mitad del siglo XX evidenciaban que tras los conflictos bipartidistas cada guerra se constituyó en un asunto de honor, orgullo y reconocimiento entre los varones de todas las edades y condiciones (Pérez, 2013).

Para las mujeres, por el contrario, eran las peores épocas de sus vidas al quedar desamparadas a cargo de los bienes familiares, pasaban necesidades y peligros, e incluso, debían curar o enterrar a sus seres queridos, extraños o al enemigo mismo. Algunas de esas viudas y huérfanas optaron por anhelar una vida mística basada en la comodidad y la paz espiritual que no se podía 
gozar de continuar sus vidas de miedos y sufrimientos en sus parroquias de origen. Un texto evidente $y$ significativo de la opinión de las mujeres acerca de un país entendible solo desde sus guerras, desde los conflictos y odios ideológicos entre los hombres obsesionados por hacer respetar el honor de su partido político, fue el poema ¿Vivir? de Silveria Espinoza, compilado por la antología de lecturas de la editorial religiosa Stella para los cursos superiores de educación básica. Con la convicción de que la pacificación del país debía darse desde las instituciones educativas públicas y privadas, de hombres y mujeres, el reclamo poético reflejaba el sentimiento ahogado y oculto de las viudas, abandonadas, violentadas o huérfanas al manifestar:

¡Vivir, vivir! ¿Y para qué Dios mío?

¿Dónde está el bien en esta ingrata tierra?

¿Dónde la paz, en la constante guerra

que sufre y que sostiene el corazón?

iVivir sin esperanza, sin amores,

Siempre aguardando en la mansión terrena

esa aurora de paz, clara y serena,

que disipe del alma la aflicción!

(Pérez, 2014, p. 57-58).

Sin embargo, esas preocupaciones melancólicas no eran compatibles con las obsesiones de los hombres y su visión del mundo sobre el honor, la lealtad, la fe y los principios que los hacía gente de bien. De allí que fuese recurrente en los diferentes textos literarios e históricos del postconflicto posterior a la Guerra de los Mil Días, el interés de militares, políticos y literatos por explicar las causas, motivos y circunstancias que propiciaron la última guerra civil declarada entre los colombianos. Joaquín Quijano Mantilla, liberal convencido y revolucionario carismático apelando a su afamada condición de periodista y cronista insigne del periódico El Tiempo, ordenó y recreó una crónica sobre las causas y consecuencias del inicio de la guerra, la cual fue publicada como parte de su Sartal de Mentiras.

Desde su perspectiva revolucionaria, y después de veinte años de pacificación de las armas como de los espíritus, Quijano cuestionaba las razones del inicio de la guerra al expresar, en oposición a sus camaradas y contemporáneos, que:

(...) Al presentarse, por la noche, en la sala de un edificio del tiempo colonial, donde lo esperaban Uribe Uribe, Juan Manuel Rudas, Ramón Neira, Cenón Figueredo y muchos otros varones ilustres, uno de ellos le dijo que expusiese el motivo de su viaje, y él extendió sobre la mesa una sencilla hoja de papel que decía: Los abajo firmados, nos comprometemos, bajo nuestra palabra, a levantarnos en armas contra el Gobierno Conservador el día 18 de octubre de 1899. Aquella era la guerra, declarada en treinta palabras. (Pérez, 2014, p. 66-67).

Laimprovisación, romanticismoycarencia deinstrucción, logística y estructura de mando entre el ejército revolucionario del altiplano, dispuesto a invadir Santander, ocupar sus ciudades provinciales e iniciar una guerra de ocupación del resto de Colombia fue recreada y divulgada por Enrique Otero D'Acosta en una de sus auto representaciones literarias. Por medio de cuentos como El Alférez Acosta, Otero reconocía sus razones y convicciones al actuar como combatiente liberal a la par de cuestionar los excesos, sevicia e inutilidad de la guerra desde su condición de próspero empresario cafetero durante las siguientes décadas de postconflicto. De sus primeras vivencias como 
revolucionario expresaba en sus Dianas Tristes:

Éramos treinta soldados del batallón "Libres". Dos horas hacía que contra vientoymarea sosteníamos una posición débilmente atrincherada sobre la pequeña colina de "Los colorados". Desde las torres de Piedecuesta y del cerrillo del cementerio nos abaleaban sin tregua ni descanso; éramos pues atacados por el flanco izquierdo y el frente. Nosotros nos defendíamos a medias, devolviendo un disparo por cada diez de los contrarios; nuestra dotación de municiones era muy escasa y había que economizarlas lo más posible. (Pérez, 2014, p. 76-77)

La batalla de Palonegro no fue solo la más larga (dos semanas), brutal y con las mayores expresiones de sevicia bélica en la historia de Colombia pues se constituyó en el combate decisivo que dio por culminada la campaña de montaña de los ejércitos enfrentados, condicionó a la retirada y reorganización del ejército liberal, así como propició la guerra de guerrillas que desgastó a los bandos hasta 1902. De allí que la guerra finalizara por un fenómeno externo como fue la amenaza de intervención e invasión armada de los Estados Unidos en defensa de sus intereses en el ferrocarril como en el canal de Panamá. (Pérez, 2015a).

Palonegro era a mediados de mayo de 1899 un sitio habitado del camino entre Girón y Rionegro, cuya casona en el alto de un cerro servía como lugar de descanso a los arrieros, quienes se recreaban jugando una variación del bolo criollo consistente en derrumbar con una bala de metal un palo negro, puesto en pie a gran distancia. Al buscar el ejército revolucionario una ruta de avanzada hacia el interior del país a través del río Lebrija y Sogamoso, el ejército nacional del norte le cerró todas las vías principales obligándolo a cruzar a través del cerro de Palonegro. Lo que empezó como fuego de disuasión el 11 de mayo por el control de la casona del cerro, terminó siendo la batalla más larga, mortífera y sanguinaria de todas las conocidas en la historia de Colombia al moverse y usarse todo el arsenal disponible por parte de ambos ejércitos.

Después de quince días de avances y retrocesos, el General P. Pinzón logró ocupar los puestos de control de los liberales entre el cerro de Palonegro y Rionegro mientras que el ejército liberal se fragmentaba hacia los páramos, Ocaña y las selvas del Magdalena. Joaquín Quijano Mantilla rememoró esos días de guerra y lucha a muerte al recordar en su Sartal de mentiras que la batalla de soldados alineados degeneró en ataques de guerrillas a posiciones estratégicas para finalmente envilecerse la lucha al atacar demencialmente los liberales con machetes y puñales, al no contarse ya con balas para defenderse:

Para mí la marcha del ejército liberal hacia Palonegro fue un descanso.

(...) Cuando llegué a la casa de Palonegro, me puse a pensar en que por voluntad propia me había puesto en un conflicto, pero ya me avergonzaba volver a mi campamento. Los heridos pasaban junto a mí en filas interminables, dejando un rastro de sangre en la arena del camino.

Se temía por la suerte de nuestra ala derecha, donde el fuego era el nutridísimo y todo el mundo pedía refuerzos y pertrechos. La noche fue horrorosa. (Pérez, 2014).

La derrota de los revolucionarios en Palonegro conllevó a que muchos de ellos decidieran rendirse, renunciar al uso de las armas y regresar a sus lugares de origen. Esos procesos de desmovilización, reinserción y resocialización fueron recreados por Ismael Enrique 
Arciniegas en el poema La balada del regreso, compilada por la editorial Librería voluntad, como parte de la antología El castellano en los clásicos de 1941. El poeta que había hecho parte activa de las guerras civiles de final de siglo, con rango y funciones militares, rememoró la experiencia del retorno de los combatientes vencedores al expresar:

\section{Son de cornetas y de tambores...}

Al pueblo vuelven los vencedores.

A su hijo entonces dice la madre:

"Ésta corona para tu padre;

Cuando lo veas, a él correrás

y la corona le entregarás".

Fueron entrando los vencedores.

Se agolpa el pueblo, iVivas y flores!

La compañía y el capitán

-son como ochenta- pasando van.

(Pérez, 2014, p. 144).

La versión de los derrotados fue de forma recurrente narrada por Enrique Otero quien hizo mención a esos días de derrota y huida en sus creaciones literarias para rememorar las vivencias de los liberales vencidos. Textos en los que cuestionaba el abandono y desorientación que vivieron al quedarse sin sus comandantes, y en especial, para denunciar el maltrato, rechazo, desprecio y condena pública que sufrieron al regresar a sus poblaciones de origen. En el cuento Agonía sangrienta denunciaba abiertamente la deshumanización en la que decayó el glorioso ejército revolucionario armado, pertrechado y entrenado durante varios meses en Cúcuta, ante lo cual recordaba a sus contemporáneos, así como cuestionaba moralmente a las próximas generaciones acerca de los efectos y defectos que generaba toda guerra civil en Colombia:

(...) Todos aquellos héroes; los del Norte, los del Sur, marchaban tristes y callados, dejando en el camino una huella dolorosa; soldados muertos, devorados por la fiebre; soldados agotados por el cansancio y el hambre, que caían de un lado a otro del camino, para no levantar jamás. En el paso del Río Grande quedaron tres infelices, sus cuerpos hinchados horriblemente, sus piernas corroídas por lepras hediondas.

Allí concluyeron la miserable jornada de su vida. Sin fuerzas para arrastrarse hasta el río, pedían desesperadamente al que pasaba "un poco de agua". Así iban quedando de uno en uno, los jirones de carne del Grande Ejército, engarzados en las zarzas del camino del Infortunio. Y quedaban estoicos, de uno a otro lado de la vía, mirando con ojos sonámbulos a sus compañeros que se iban, se iban abandonándolos en su desgracia, sin poder hacer nada por ellos (Pérez, 2014, p. 147-148).

\section{CONCLUSIONES}

Todo conflicto armado regular e irregular conlleva a la definición de un vencedor y un vencido. Y con ello, a la imposición de un relato nacional por parte del guerrero triunfante, así como a la publicación de réplicas y defensas editoriales por parte del vencido, en nombre de su honor y el de sus compañeros de armas.

Ambos discursos, en el caso de la posguerra y la pacificación de Colombia después de la Guerra de los Mil Días conllevaron a la publicación de narraciones, 
poemas y artículos literarios en los cuales gradualmente la versión del vencido fue considerada válida al abogar por valores comunes como el amor a la patria, la pacificación de los espíritus y la visión productiva del país, siendo ese espíritu de reflexión, cuestionamiento y pacificación compilado por las editoriales religiosas en las antologías literarias empleadas, recomendadas o adoptadas como libros oficiales de lectura por los gobiernos nacionales.

Una de las innovaciones editoriales más exitosas para reafirmar los principios y valores de la pacificación fueron los textos de lectura y ortografía de uso en los cursos de educación primaria y secundaria. Los relatos y las representaciones literarias de los escritorese intelectuales más reconocidos del país buscaron equilibrar el discurso histórico de lo vivido con el papel moral que podía tener el discurso literario.

De allí la insistencia en temáticas comunes como el buen uso de la prensa, la idolatría por la patria y los juramentos de dar la vida por defenderla de cualquier invasor externo $y$, el uso de la lengua castellana como instrumento para reafirmar la hermandad nacional, cuestionar la solución bélica de las diferencias y propender por la convivencia y la pacificación nacional como reflejo del último postconflicto vivido en Colombia.

\section{REFERENCIAS}

Anónimo (1934). Las Aventuras de Rosendo. Colombia: [facsímil impreso].

May, G. (1982). La autobiografía. México: Fondo de Cultura Económica.

Pérez, V. (1972). "La autobiografía en la literatura colombiana", En Noticias culturales, (132).

(1996). La autobiografía en la literatura colombiana. Bogotá: Presidencia de la República.

Pérez, L. (2012). “El General José Santos: Héroe y villano de la Regeneración", En Martínez, A. Una familia Santos de Santander y Colombia. Bucaramanga: Sic. P. 113-398

(2013). Historiar la Muerte II. Representaciones sociopolíticas sobre el buen "morir por la patria" entre los revolucionarios de Colombia. Bucaramanga: Publicaciones UIS-Luis Rubén Pérez Pinzón.

(2014). Narrativas del Último Postconflicto. Antología literaria sobre la 'Guerra de los Mil Días' (Del aprendizaje de la "Cultura de la Violencia" a la didáctica de la "Cultura de la Paz"). Bucaramanga: Luis Rubén Pérez Pinzón.

(2015a). Narrativa, memoria y heroísmo empresarial. Bucaramanga: Publicaciones UIS-Luis Rubén Pérez Pinzón.

(2015b). "Reflexiones morales sobre la guerra y la paz en los textos escolares usados después de guerra de los mil días", En Memoria y Sociedad, 19 (38): 60-74

Citar este artículo como: Pérez, L. (2017). “Manuales de lectura y pacificación nacional durante el último postconflicto en Colombia". En: Revista La Tercera Orilla (18). Bucaramanga: Universidad Autónoma de Bucaramanga. 